\title{
VIRILIZING ADRENAL HYPERPLASIA; A GENETIC AND HORMONAL STUDY ${ }^{1}$
}

\author{
By BARTON CHILDS,2 MELVIN M. GRUMBACH, ${ }^{3}$ AND JUDSON J. VAN WYK * \\ (From the Harriet Lane Home, Johns Hopkins Hospital and the Department of Pediatrics, \\ The Johns Hopkins University Medical School, Baltimore, Md.)
}

(Submitted for publication August 19, 1955 ; accepted October 17, 1955)

It is not at all unusual to find other affected children among the brothers and sisters of patients with virilizing adrenal hyperplasia. Such familial aggregations of affected children suggest, at least, a genetic basis for the condition at hand, and when the affected individuals are distributed in one generation only, there is a possibility that the condition is due to a mutant gene which finds obvious expression in the homozygote. This mode of inheritance for a possible gene responsible for virilizing adrenal hyperplasia has been suggested (1-3). Knudson (2) obtained information on 8 families, including 11 affected children. To these he added 26 families taken from the literature in which there were 32 affected children. Comparison of the observed number of affected sibs of index cases with that expected indicated sufficient agreement to favor the hypothesis of a recessive gene. All of Knudson's cases, however, were patients who showed evidence of electrolyte disturbance, and there appears to be no study which includes all types of cases which fall into this syndrome. This paper consists of information pertaining to a possible genetic etiology of this disease, obtained from 56 families containing one or more affected individuals, and an hormonal study of a group of parents of affected children. An exhaustive review of the literature is not relevant here, since our interpretations are based only upon the results of the analysis of our own data and not upon information from families that has been presented in other articles.

\footnotetext{
1 Supported in part by a grant from the Division of Research Grants and Fellowships of the National Institutes of Health, United States Public Health Service.

2 John and Mary Markle Scholar in Medicine.

8 Fellow, National Foundation for Poliomyelitis. Present address: Babies Hospital, New York City, N. Y.

- Fellow, National Foundation for Poliomyelitis. Present address: Department of Pediatrics, Medical School, University of North Carolina, Chapel Hill, N. C.
}

\section{MATERIALS AND METHODS}

The data were obtained from the families of all patients with virilizing adrenal hyperplasia who were examined and diagnosed in the endocrine clinic of the Harriet Lane Home since 1945. Diagnostic criteria are those given by Wilkins (4). In each instance the information was given by the mother or responsible parent, and in a few cases by the patient himself. Some questions were put by means of a questionnaire which was mailed to all families, but since in some cases parents failed to answer the questionnaire and were otherwise unavailable, the data are in certain aspects incomplete.

The data consist of information pertaining to: disease in sibs and other relatives, together with intra-family characteristics of the disease; age of sibs, their sex, maternal age at birth, birth order, death, age, cause, and place of death; maternal gestation and parturition; parental consanguinity; and size of the families of both parents.

In some families all affected children were patients of the endocrine clinic, but there were 12 sibs of endocrine clinic patients who are presumed to have or have had the disease, who have never been seen in the Harriet Lane Home. Of these, 3 are still living, and detailed inquiry reveals that a firm diagnosis has been made on all three. The remaining 9 were dead by the time the index case was seen here. A diagnosis, either during life or at autopsy, was made elsewhere on 5 of these. This leaves 4 cases who were dead and who were not diagnosed as patients with virilizing adrenal hyperplasia either during life or at death. The history of these 4 children was, however, compatible with the disease. All were males without genital abnormalities, who though normal at birth failed to thrive and died in the early weeks of life with dehydration, diarrhea, and vomiting, often accompanied by pneumonia. Sibs dead of unknown causes were excluded.

\section{Measurement of urinary 17-ketosteroids, pregnanetriol, and pregnanediol}

Urinary 17-ketosteroids were determined by a modification of the method of Callow, Callow, and Emmons (5). Fifty-ml. aliquots of freshly collected 24-hour urine specimens from 18 normal adult male and female subjects and 20 parents of patients with virilizing adrenal hyperplasia were incubated with a beef liver preparation of betaglucuronidase (Ketodase, Warner-Chilcott Laboratories) 
for 24 hours at $37^{\circ} \mathrm{C}$ after adjusting the $\mathrm{pH}$ to 4.5 with $2 \mathrm{~N}$ acetate buffer, and the hydrolysate was extracted with benzene. The benzene extract was washed with 1.0 $\mathrm{N}$ sodium hydroxide and distilled water, evaporated, and the residue dissolved in $5.0 \mathrm{ml}$. of benzene with gentle heat, applied to an alumina (Harshaw Chemical Co.) column, and chromatographed according to the method of Bongiovanni and Clayton (6) as devised in this laboratory. No preliminary Girard separation was performed. The 2 per cent ethanol in benzene eluate was used to determine pregnanediol chromogen, and the 10 per cent ethanol in benezene fraction was employed to determine pregnanetriol chromogen. Both fractions were dried with a stream of air, the residue redissolved in $5.0 \mathrm{ml}$. of ethanol to complete removal of any residual benzene, and again evaporated to dryness. Pregnanediol and pregnanetriol chromogens were obtained by adding $10.0 \mathrm{ml}$. of sulfuric acid (A.R.) to the dried residue, and the chromogen formed was read after 20 minutes with the Beckman D.U. quartz spectrophotometer at the following wave lengths: $325,390,425,440,460 \mathrm{mu}$. The total quantity of each substance was calculated by the use of the corrected coefficient of extinction at $425 \mathrm{mu}$, as previously described (6). For pregnanetriol to be considered present, the sulfuric acid chromogen of the unknown was required to conform to the spectrum of pure pregnanetriol in sulfuric acid. The rapid addition of water to the sulfuric acid chromogen of pregnanetriol consistently produced a transient pink color as observed by Bongiovanni, Eberlein, and Cara (7). In addition, a comparison of acetaldehydogenic substances in the residue of the 10.0 per cent ethanol in benzene eluate after periodate oxidation according to the method of Cox (8) has shown good agreement in this laboratory with the determination of pregnanetriol by the chromogen formed with sulfuric acid: the former measures C 17-, 20-dihydroxy, 21-methyl steroids. Furthermore, as pointed out previously $(6,7)$, the application of this method has resulted in the isolation of crystalline pregnane-3 $\alpha, 17 \alpha, 20 \alpha$ triol, the identity of which has been confirmed by infra-red spectroscopy.

ACTHAR gel,5 40 I.U. per ml., was administered intramuscularly between 8 A.M. and 9 P.M. in a dosage of 60-80 I.U. daily for one to two days. The group of normal adults all received at least 80 I.U. daily, while in several instances parents of affected individuals received 60 I.U. in a single dose. Urine was collected the day prior to administering the ACTH and during the 24-hour period after each injection of ACTH. The urine was preserved with $5 \mathrm{ml}$. of toluene.

\section{RESULTS}

There were 76 affected individuals among 181 sibs in 56 families. There were no affected parents, grandparents, uncles, aunts, or cousins.

5 Lot No. N-33107. We are indebted to Dr. J. A. Hubata and the Armour Company for contributing this preparation.
Among genetic hypotheses this distribution suggests a gene which manifests itself only in the homozygote. Alternatively the disease might not be genetically determined at all, but might be due to an environmental effect, possibly an effect of the maternal, intra-uterine environment. These two possibilities we have examined in detail.

It is perhaps unlikely that this condition could be due to an effect of the maternal environment for the following reasons: 1) These patients have a metabolic defect which is operative throughout life, and sometimes showing no clinical manifestations until after birth, whereas defects due to intra-uterine factors are fixed at the time of birth and do not change, except as growth and development may alter and distort their effects. 2) $\mathrm{Fe}$ male pseudohermaphrodites born to mothers with arrhenoblastoma show no additional virilization after birth (9). 3) Genital defects produced in the offspring of animals to whom androgens have been administered during pregnancy may be similar to those exhibited by patients with virilizing adrenal hyperplasia, but these are fixed at birth, and no further virilization ensues $(10,11)$. 4) There is a striking similarity between the proposed pathogenesis of this disease $(6,12-17)$, and biochemical defects in a variety of organisms for which there is excellent evidence for gene control.

These reasons do not rule out this possibility, but make it somewhat less satisfying than the alternative possibility of genetic control. An analysis of the data for the operation of certain maternal factors will be given later in the paper.

Evidence favoring the hypothesis of a single, autosomal, recessive gene depends upon the fulfillment of several criteria. We have used those given by Penrose (18). If this disease were due to such a gene we should find: clear distinction between affected and unaffected; a ratio of one affected to 3 healthy offspring of unaffected parents, boys and girls showing the disease with equal frequency; if the disease is uncommon, a higher incidence of first cousin matings among the parents of affected children than among the general population, and occasional cases appearing among the collateral relatives.

\section{Distribution of affected within families}

A glance at Table I reveals that considerably more than one quarter of the children are affected. 
TABLE I

Factorial method of testing recessive hypothesis on families containing cases of virilizing adrenal hyperplasia

\begin{tabular}{|c|c|c|c|c|c|c|}
\hline \multirow{3}{*}{$\begin{array}{l}\text { Size of } \\
\text { sibship } \\
\text { S }\end{array}$} & \multirow{3}{*}{$\begin{array}{l}\text { No. of } \\
\text { sibships } \\
\text { of size S } \\
\mathrm{N}_{8}\end{array}$} & \multirow{3}{*}{$\begin{array}{l}\text { Total } \\
\text { No. of } \\
\text { sibs } \\
\mathrm{S} \times \mathrm{N}_{\mathrm{s}}\end{array}$} & \multicolumn{3}{|c|}{ Number of affected sibs } & \multirow{3}{*}{$\begin{array}{l}\text { Variance of } \\
\text { expected } \\
\text { number }\end{array}$} \\
\hline & & & \multicolumn{2}{|c|}{ Observed } & \multirow{2}{*}{$\begin{array}{c}\text { Expected } \\
\mathrm{S} \times \mathrm{N}_{\mathrm{N}} / \mathbf{4}[1-(3 / 4) \cdot]\end{array}$} & \\
\hline & & & Obs. & Presumed & & \\
\hline \multirow{10}{*}{$\begin{array}{r}1 \\
2 \\
3 \\
4 \\
5 \\
6 \\
7 \\
8 \\
9 \\
10 \\
11\end{array}$} & 8 & 8 & 8 & & 8.00 & 0.000 \\
\hline & 16 & 32 & 18 & (20) & 18.28 & 1.956 \\
\hline & 14 & 42 & 22 & (23) & 18.16 & 3.682 \\
\hline & 9 & 36 & 13 & (14) & 13.17 & 3.780 \\
\hline & 3 & 15 & 4 & & 4.92 & 1.776 \\
\hline & 2 & 12 & $\overline{2}$ & & 3.65 & 1.552 \\
\hline & 1 & 7 & 1 & & 2.02 & 0.970 \\
\hline & 2 & 18 & 2 & & 4.87 & 2.760 \\
\hline & & & & & & \\
\hline & 1 & 11 & 2 & & 2.87 & 1.805 \\
\hline Totals & 56 & 181 & 72 & 76 & 75.94 & 18.281 \\
\hline
\end{tabular}

Difference $=75.95-72=3.95$.

S.E. $=\sqrt{ } 18.281=4.28$

$$
\begin{gathered}
\frac{\text { Difference }}{\text { S.E. }}=\frac{3.95}{4.28}=0.92 . \\
\text { Difference }=76-75.95=0.05 . \\
\frac{\text { Difference }}{\text { S.E. }}=\frac{0.05}{4.28}=0.01 .
\end{gathered}
$$

This may be due to the fact that many of the families are small, and only families which contain at least one affected child have come into the data. We may test this possibility by comparing our figures with expectation according to various family sizes, assuming the actual proportion of affected to unaffected to be precisely $1: 3$. Table I sets out these calculations according to a method devised by Hogben (19). It will be seen that there is good agreement between the number of observed cases and expectation, and indeed, the difference between observed and expected is less than the standard error whether we include the four presumed cases or not. In addition, the agreement within categories according to family size is good.

Haldane has devised a somewhat different method by which one may estimate the true proportion of affected children from the data, which may then be compared with the proportion to be expected (20). This calculation gives a proportion of 0.2507 with a standard error of 0.0139 , a value which agrees very well with the expected proportion of 0.25 .

These calculations do not of themselves prove that adrenal hyperplasia is due to a recessive gene, but do indicate that the distribution of affected children in the families in the data does not differ significantly from that expected if the disease were due to such a gene.

In addition here is further evidence against a maternal factor, since if a maternal factor were causing the defect, we would not expect such good agreement between observation and expectation within each family size category.

\section{Gene frequency}

Assuming for the moment that virilizing adrenal hyperplasia is genetically determined, it is relevant to the analysis of our data to estimate the gene frequency. This estimate will necessarily be imprecise, but nevertheless useful.

To do this we must know the incidence of the disease, a figure difficult to find, particularly if the disease is rare, or affects viability. For example, some cases of adrenal hyperplasia would go unrecognized through neonatal death, or through ignorance of the parents, and some males with delayed virilization might be regarded as instances of precocious puberty and thus be lost. In addition, any one physician or institution will have no more than a sample, be it large or small, of the total.

The possibility of making a minimum estimate in the state of Maryland is perhaps favorable, since circumstances make it likely that the ma- 
jority of patients who come to the attention of physicians at all, will find their way to the endocrine clinic at the Harriet Lane. A rough incidence may therefore be calculated by comparing the number of affected patients born in Maryland with the number of births in the state since $1939,{ }^{\circ}$ the year 1939 being chosen because the eldest child in the group was born in that year. There were twelve patients born in Maryland during this interval, against 798,118 live births in the state. This gives an estimate of the incidence of the disease in Maryland of one per 67,000 births. It is of interest that but one colored patient, appeared in the entire series. This is doubtless due in part to social factors, but may also represent a different incidence of the disease among negroes.

We may now estimate the gene frequency by means of the Hardy-Weinberg Law, obtaining a value of 0.0039 and an incidence of heterozygotes of 0.0078 or one per 128 individuals in the general population. It should be emphasized that these estimates are crude, and that the true values are certainly higher than these. But the calculations are perhaps worthwhile in indicating that though the disease may be rare, the presumed gene would exist in rather large numbers in heterozygotes in the population.

\section{Consanguinity}

In our series there was only one family, in which the parents were related in any way, and these were first cousins. The finding of one consanguineous union in this series could be fortuitous, but it is possible to calculate how many such matings one would expect, using the gene frequency value we have already estimated.

This calculation (Dahlberg [21]) requires an estimate of 1 st cousin marriages in the general population, and for this figure we have used the incidence quoted by Glass (22) of one per 2000 marriages, based upon interviews with 8000 Maryland families. The calculation reveals an expectation of one first cousin marriage per 120 families, a ratio considerably higher than that in the general population. We have found one in 47 families. Thus we may take it that we would not expect more than one consanguineous mating among our families, but it is not surprising that

- These figures were kindly furnished by Dr. Edward Davens of the Maryland State Health Department. one does appear. Consanguinity has been reported in a number of families reported in the literature $(2,3)$.

\section{Collateral relatives}

We did not find any affected individuals among the uncles, aunts, and cousins. The disease is obviously rare, and even if the gene frequency were 2 or 3 times as great as our estimate, the incidence of the disease among collateral relatives would be so small as to be unexpected in 56 families.

\section{Sex ratio}

If the proposed gene is an autosomal recessive it ought to be distributed equally among males and females. The data, however, reveal a heavy preponderance of females. One possibility is that the surplus of females might be due to biases in the ascertainment of cases, and the data were therefore examined with this possibility in mind. The proportion of males among all cases was 0.43 . Considering only the index case in each family the deficiency of males is even greater $(0.33)$, suggesting that females may be more readily ascertained than males, probably because of genital abnormalities as well as the striking contrast between their sex and the evidence of virilism. On the other hand, some families containing only males who may show less striking abnormalities, might not enter a series such as this because of failure to recognize them.

If, on the other hand, both males and females are equally prone to the electrolyte imbalance seen early in life in this disease, we might see a more equal distribution of the sexes among these patients. In such cases a true diagnosis is more likely to be made, because of the urgent need for correct diagnosis and treatment of the disease at this stage. In our data, a comparison of males and females among salt losers reveals a proportion of 0.65 males. The bias of ascertainment may be eliminated altogether if we consider only those patients in our families who were discovered after a diagnosis had been made on the index case. There were twenty of these, 9 males and 11 females. This ratio does not depart markedly from unity, and suggests that males are affected equally with females. This information is summarized in Table II. 
TABLE II

Ratio of males to females among patients with virilizing adrenal hyperplasia

\begin{tabular}{lcccc}
\hline \hline & Males & Females & Totals & $\begin{array}{c}\text { Sex-ratio } \\
\text { M/F }\end{array}$ \\
\hline Index cases & 14 & 42 & 56 & 0.33 \\
All cases & 23 & 53 & 76 & 0.43 \\
Salt losers & 11 & 17 & 28 & 0.65 \\
Affected sibs & 9 & 11 & 20 & 0.82 \\
\hline
\end{tabular}

\section{Clinical heterogeneity}

It is well known that virilizing adrenal hyperplasia shows a varied clinical picture. In addition to virilism some patients show electrolyte disturbances, and some are hypertensive. There is also some variation in age of onset. That is, some females exhibit enlargement of the clitoris and urogenital sinus at birth, others have only clitoral enlargement, and a few are quite normal at birth and show delayed onset of virilization. In boys, signs of the disease may consist only of electrolyte disturbance in the neonate, or the onset of virilism may be delayed for a variable length of time.

It was a matter of some interest to examine the data to see whether this heterogeneity existed between or within families. There were 16 families that contained at least one affected child who showed electrolyte imbalance. Of these, 9 families had two affected children, both of whom were salt losers, and in one family there were 3 such patients. There were no families containing more than one affected child in which one was a salt loser and others were not.

Three families contained at least one affected child who was hypertensive. Of these, two contained two patients, both hypertensive. None of these patients were also salt losers.

There were four families in which affected females had either normal genitalia at birth, or some degree of clitoral enlargement without a urogenital sinus. In 3 of these there were female sibs who showed a similar picture at birth. Two pairs of these girls are also hypertensive.

In one family there were two boys, the onset of whose disease was delayed until each was about 6 years. Table III summarizes this information for 18 families which contained two or more affected children.

Thus it is clear that in this series the hetero- geneity of the clinical picture of the disease appears between families, but not within. In each family the manifestations were always the same in affected sibs, salt loss and hypertension did not occur together, and in none of the cases in which the onset was delayed was an electrolyte disturbance found. For this kind of analysis the numbers of cases are small, so that some or all of these conclusions may be erroneous. Confirmation or rejection will have to await the analysis of additional data.

\section{Maternal factors and family size}

It is pertinent to examine the effects of genes on the fertility of their carriers. If adrenal hyperplasia is genetically determined, and present only in homozygotes, then both parents must be heterozygous. The question arises whether a gene which in the homozygote renders the victim sterile, might have some effect upon the ability of the heterozygous mother to conceive and bear children.

Pregnancy losses of 51 mothers were investigated and found to amount to 9.94 per cent of all pregnancies. There were perhaps other early miscarriages unknown to these mothers, but this rate is certainly not extraordinary (23).

In addition we have looked for evidences of effects which might be expressed in the gestational characteristics of the mother, such that maternal age or parity might influence the manifestation of the disease in her offspring. This information consists of a comparison of numbers of offspring observed at various birth ranks and maternal ages at births of affected children, with expectation. The method is due to Penrose (24). Table IV shows this comparison and indicates that no noticeable effect was found. There were no diffi-

TABLE III

Indicating heterogeneity of clinical syndromes between, but homogeneity within 18 families containing more than one affected child

\begin{tabular}{lcrcccc}
\hline \hline & & \multicolumn{4}{c}{ Sibs } \\
\cline { 3 - 6 } $\begin{array}{c}\text { Type of } \\
\text { disease }\end{array}$ & $\begin{array}{c}\text { Number } \\
\text { of index } \\
\text { cases }\end{array}$ & $\begin{array}{c}\text { Salt } \\
\text { losers }\end{array}$ & $\begin{array}{c}\text { Hyper- } \\
\text { tension }\end{array}$ & $\begin{array}{c}\text { Virilism } \\
\text { only }\end{array}$ & Totals \\
\hline Salt losers & 10 & 11 & 0 & 0 & 21 \\
Hypertension & 2 & 0 & 2 & 0 & 4 \\
Virilism only & 6 & 0 & 0 & 7 & 13 \\
Totals & 18 & 11 & 2 & 7 & 38 \\
\hline
\end{tabular}


culties on the part of the mothers in achieving pregnancy, nor were there any significant histories of complications during pregnancy or labor.

Inquiry into the total numbers of offspring produced by the mothers in our series, as well as the sizes of the families whence they and the fathers came revealed that the mean family size of the fathers was 4.1 sibs, of the mothers 3.8 sibs, and of the patients, 3.2 sibs. It is evident that families containing possible carriers of the gene are not reduced in size, nor are sibships containing affected individuals, even though the latter are not in all cases completed families.

In sum, it may be said that no factors influencing conception, gestation or fertility, nor any maternal influence on the disease have been found.

\section{Expression in possible heterozygotes}

If it be assumed that every gene has a measurable effect if it could be detected, it is worthwhile to seek the manifestations in heterozygotes of genes which are expressed fully only in homozygotes. The detection of such an effect in the heterozygote in fact puts the hypothesis that the condition is heritable on much firmer ground. Since both parents of any homozygote must be heterozygous for the particular gene in question, these individuals would be the most likely ones to study for manifestations in the carrier.

Evidence has recently been presented to indicate that the primary defect in virilizing adrenal hyperplasia consists of failure of the adrenal cortex in the synthesis of compound F (12-16). In accordance with the scheme of adrenocorticosteroid biogenesis suggested by Hechter and his co- workers (25), Jailer has suggested that a block exists in the conversion of $17 \alpha$ hydroxyprogesterone into compound F (17). Substantiation of Jailer's hypothesis has been given by the demonstration by Bongiovanni and his co-workers that $3 \alpha-17 \alpha-20 \alpha$-pregnanetriol is the steroid found in greatest quantity in the urine of affected patients $(6,7,26,27)$. In addition, administration of ACTH to patients with adrenal hyperplasia has caused a rise in urinary pregnanetriol, frequently of greater magnitude than the increase of 17-ketosteroids $(7,26)$. Pregnanetriol has also been shown to be a metabolite of 17-hydroxy-progesterone by recovery and identification of this steroid from the urine of a 10-year-old boy with Addison's disease, as well as from adrenalectomized rabbits to which 17-hydroxy-progesterone had been administered parenterally (28). Thus the synthetic transformations involving the conversion of 17 hydroxy-progesterone to compound $F$ may well include a blocked step which could be due to a mutant gene.

This possibility suggested an approach to the detection of heterozygotes. It is clear that the heterozygote performs adequately the synthesis which is blocked in the homozygote, but excessive stimulation of the adrenal cortex of the carrier might stress this pathway of synthesis so as to reveal a normally concealed defect. This might result in abnormal increase in urinary pregnanetriol.

Measurements were therefore made of pregnanetriol in the urine of 20 parents before and after stimulation with $\mathrm{ACTH}$, in order to determine whether or not a rise in this metabolite would

TABLE IV

Comparison of observed and expected numbers of patients with virilizing adrenal hyperplasia according to birth rank and maternal age

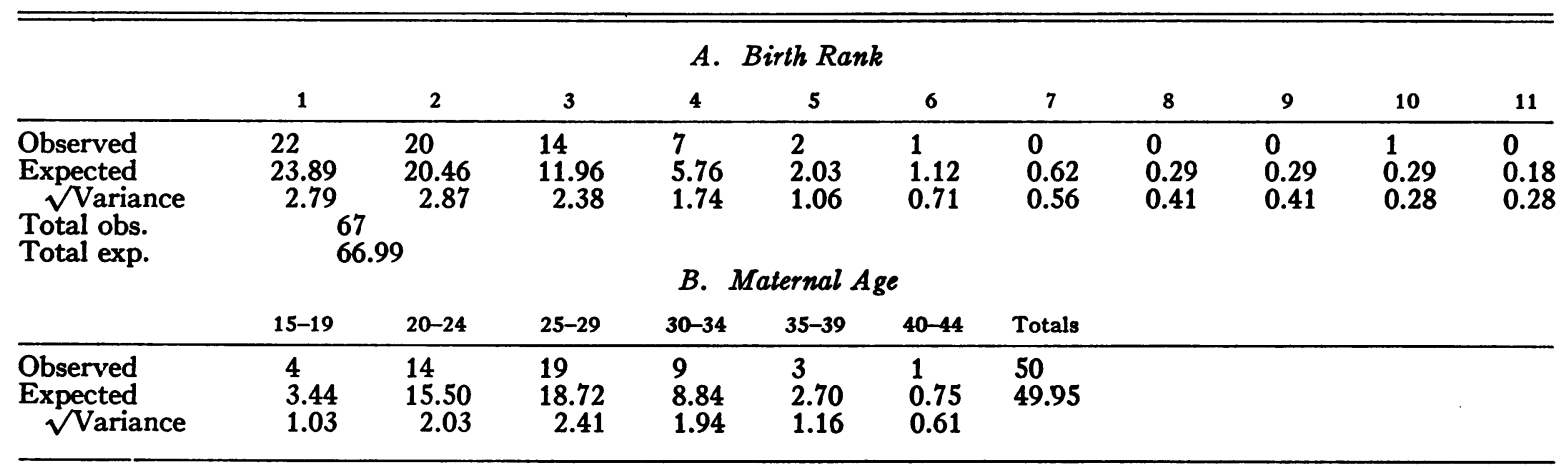


TABLE V

Twenty-four hour excretion of pregnanetriol of 18 normal controls and 20 parents of patients with virilizing adrenal hyperplasia

\begin{tabular}{|c|c|c|c|c|c|c|c|c|c|}
\hline \multicolumn{5}{|c|}{ Controls } & \multicolumn{5}{|c|}{ Parents } \\
\hline \multirow[b]{2}{*}{ Sex } & \multirow[b]{2}{*}{ ACTH } & \multicolumn{3}{|c|}{ Pregnanetriol mg./day } & \multirow[b]{2}{*}{$\operatorname{Sex}$} & \multirow[b]{2}{*}{ ACTH } & \multicolumn{3}{|c|}{ Pregnanetriol mg./day } \\
\hline & & Initial & $\begin{array}{c}\text { Post } \\
\text { ACTH }\end{array}$ & Increment & & & Initial & $\begin{array}{c}\text { Post } \\
\text { ACTH }\end{array}$ & Increment \\
\hline $\begin{array}{l}\mathbf{M} \\
\mathbf{M} \\
\mathbf{F} \dagger \\
\mathbf{M} \\
\mathbf{F} \\
\mathbf{M} \\
\mathbf{M} \\
\mathbf{M} \\
\mathbf{F} \\
\mathbf{F} \\
\mathbf{F} \\
\mathbf{F} \\
\mathbf{M} \\
\mathbf{F} \\
\mathbf{M} \\
\mathbf{M} \\
\mathbf{F} \\
\mathbf{F}\end{array}$ & $\begin{array}{l}80 \\
80 \\
80 \\
80 \\
80 \\
80 \\
80 \\
80 \\
80 \\
80 \\
80 \\
80 \\
80 \\
80 \\
80 \\
80 \\
80 \\
80\end{array}$ & $\begin{array}{l}1.6 \\
1.2 \\
1.2 \\
1.5 \\
1.3 \\
2.6 \\
3.1 \\
1.6 \\
2.0 \\
0.4 \\
1.4 \\
0.5 \\
1.3 \\
1.8 \\
1.5 \\
1.0 \\
1.7 \\
2.6\end{array}$ & $\begin{array}{l}3.1 \\
2.0 \\
5.6 \\
2.0 \\
3.1 \\
3.4 \\
3.3 \\
1.6 \\
2.4 \\
1.0 \\
1.9 \\
1.8 \\
1.7 \\
3.4 \\
2.6 \\
2.1 \\
2.6 \\
4.1\end{array}$ & $\begin{array}{l}1.5 \\
0.8 \\
4.4 \\
0.5 \\
1.8 \\
0.8 \\
0.2 \\
0.0 \\
0.4 \\
0.6 \\
0.5 \\
1.3 \\
0.4 \\
1.6 \\
1.1 \\
1.1 \\
0.9 \\
1.5\end{array}$ & $\begin{array}{l}F \dagger \\
M \\
F \\
M \\
F \\
M \\
F \\
M \\
F \\
M \\
F \\
F \\
M \\
F \\
M \\
F \\
M \\
M \\
M \\
F\end{array}$ & $\begin{array}{l}80 \\
80 \\
80 \\
80 \\
60 \\
60 \\
80 \\
80 \\
60 \\
60 \\
80 \\
60 \\
60 \\
80 \\
80 \\
80 \\
80 \\
80 \\
80 \\
80\end{array}$ & $\begin{array}{l}0.85 \\
0.00 \\
0.44 \\
1.10 \\
1.40 \\
0.95 \\
0.57 \\
1.30 \\
0.52 \\
1.20 \\
0.66 \\
1.10 \\
0.81 \\
0.75 \\
0.48 \\
3.70 \\
1.40 \\
5.60 \\
1.6 \\
0.27\end{array}$ & $\begin{array}{r}10.5 \\
1.2 \\
3.9 \\
2.3 \\
3.9 \\
2.1 \\
2.8 \\
5.0 \\
1.6 \\
2.4 \\
1.9 \\
1.9 \\
1.3 \\
2.9 \\
2.1 \\
6.3 \\
2.1 \\
46.9 \\
2.8 \\
0.9\end{array}$ & $\begin{array}{c}9.7 \\
1.2 \\
3.5 \\
1.2 \\
2.5 \\
1.1 \\
1.7 \\
3.7 \\
1.1 \\
1.2 \\
1.2 \\
0.8 \\
0.4 \\
2.2 \\
1.6 \\
2.6 \\
0.7 \\
41.3^{*} \\
1.2 \\
0.5\end{array}$ \\
\hline $\begin{array}{r}\mathrm{Me} \\
\mathrm{S}\end{array}$ & Means & 1.59 & 2.65 & $1.06 \pm 0.30$ & & & 1.01 & 3.05 & 2.04 \\
\hline
\end{tabular}

* Not included in mean.

† Pregnant.

appear. In addition, 17-ketosteroid and pregnanediol determinations were run on the same specimens. As controls, 18 normal, unrelated individuals, both male and female, in a sex distribution approximately equal to that of the parent group were stimulated in the same manner and the same determinations were made. Table $\mathrm{V}$ shows the results among both controls, and parents. It should be noted that one extremely high parent value has not been included in computing the mean. This parent showed an increment of 41.3 mg. per day. This value was checked by a second collection of urine following a second dose of $\mathrm{ACTH}$, and on this occasion the pregnanetriol excretion was $43.9 \mathrm{mg}$., representing an increment of $38.3 \mathrm{mg}$.

A test of significance of the difference between the increments of parents and controls gave a $\mathrm{p}$ value lying between 0.02 and 0.05 , suggesting that the difference was a significant one (29). Thus we may say that though the number of our observations is small, the difference in increments between the two groups is significant, although not highly significant.
When frequency distributions of the two sets of values were drawn up, though there was much overlapping, much of the parent curve lay to the right of that of the controls, showing graphically

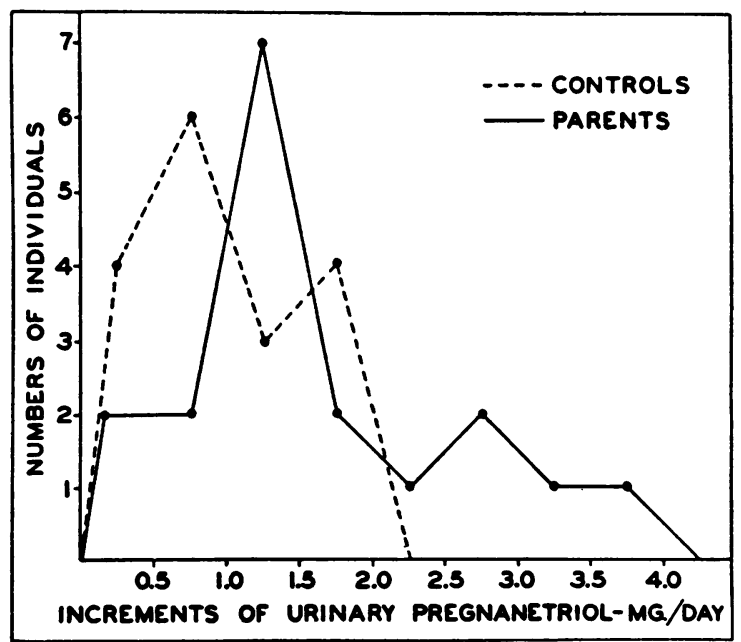

Fig. 1. Frequency Distributions of InCREMents of Pregnanetriol Excretion Following ACTH Strmulation of 17 Controls and 18 Parents of Affected INDIVIDUALS 
TABLE VI

Mean excretion of pregnanediol by parents and controls before and after stimulation with $A C T H$

\begin{tabular}{lcccc}
\hline \hline & \multirow{2}{*}{$\begin{array}{c}\text { Number } \\
\text { of } \\
\text { subjects }\end{array}$} & Initial & ACTH & Increment \\
\cline { 3 - 5 } & 13 & 2.61 & 4.72 & $2.12 \pm 0.63$ \\
\hline Parents & 10 & 3.19 & 5.32 & $2.24 \pm 1.14$ \\
Controls & 10 & & & \\
\hline
\end{tabular}

the difference between the two groups. These curves are shown in Figure 1. In drawing the curves, the two highest values among the parents, and the highest value among the controls have been removed.

In Tables VI and VII are set out the mean excretion values of 17 -ketosteroids and pregnanediol both before and after administration of ACTH, along with their mean increments. No significant differences were found here.

\section{DISCUSSION}

The proof of heritability of any disease among humans remains a difficult problem. It depends upon two types of evidence: a) statistical analysis of family data to determine conformity with criteria specific to particular Mendelian hypotheses, and b) observation of a biochemical abnormality which can be understood in terms of gene control.

Though the analysis of our data does not prove the presence of a heritable factor to the same degree that breeding experiments will do so, the results are at least quite compatible with the presence in these families of a gene which produces virilizing adrenal hyperplasia in homozygotes. The alternative, intra-uterine influence though not to be dismissed, seems less likely.

The statistical analysis, tells us nothing of the nature of the action of the gene, nor whether the condition is genetically homogeneous. For that

TABLE VII

Mean twenty-four hour excretions of 17-ketosteroids of parents and controls, including test of significance of difference in increments after $A C T H$

\begin{tabular}{ccccc}
\hline \hline & $\begin{array}{c}\text { Number } \\
\text { of } \\
\text { subjects }\end{array}$ & Initial & $\begin{array}{c}\text { Post } \\
\text { ACTH }\end{array}$ & Increment \\
\cline { 2 - 5 } & 20 & 6.68 & 11.82 & $5.14 \pm 1.54$ \\
\hline Parents & 18 & 9.19 & 11.72 & $2.52 \pm 1.09$ \\
Controls & & & & \\
$\mathbf{t}=1.55$. & & & & \\
$\mathrm{P}=>0.1$. & & &
\end{tabular}

information we must consider those clinical and biochemical characteristics which may be observed and measured.

It is apparent that there are variations in the clinical picture of the disease and that this heterogeneity exists between, but not within, families. More information is needed to confirm these observations, and if this is forthcoming, this heterogeneity may ultimately come to be understood in genetical terms. That is, it suggests the segregation in particular families of different genes, possibly a system of alleles at one locus, or alternatively different genes at different loci, controlling different biochemical events but producing phenotypic similarities. Evidence indicating that there may be more than one biochemical defect has been given by Bongiovanni and Eberlein who found distinctive chemical characteristics in a patient with virilizing adrenal hyperplasia and hypertension $(30,31)$.

As a possible manifestation of the carrier state, we have looked for evidence of increased excretion of pregnanetriol by parents of patients. The rise in excretion of this compound by parents, following stimulation with $\mathrm{ACTH}$, was slightly greater than that of the controls, and differed significantly but not highly from the latter. In addition, two of the parents showed increments far in excess of any shown by the control individuals. The true meaning of these observations will have to await confirmation, but the finding does add some weight to the concept that this disease is determined by a mutant gene. It is probably worthwhile to search for other characteristics which might be more definitive manifestations of the trait. It should be emphasized that ACTH stimulation and subsequent determination of pregnanetriol excretion could not, except in an occasional instance, serve to pick out an heterozygote from the general population.

\section{SUMMARY}

1. Information obtained from 56 families which contained 76 patients with virilizing adrenal hyperplasia has been analyzed. Comparison of the observed numbers of patients with that expected upon the hypothesis of an autosomal recessive gene responsible for the condition showed good agreement. There was one consanguineous mating among 46 families, an incidence which would 
be expected on the basis of a calculated minimum gene frequency. It is probable that, though there were many more affected girls than boys in the series, the preponderance of females is due to biases in ascertainment of the cases, most likely because of the abnormality of the female genitalia. The fertility of the parents and grandparents was not reduced. There were no evident deleterious effects on gestation or labor in the mothers, nor any evidence of maternal influence on manifestations of the diseases.

2. Among these cases the clinical pattern of the disease was consistent within families in which more than one case existed, but varied between families. This suggests that there may be genetic as well as clinical heterogeneity.

3. Attempts were made to detect the effects of a possible gene in the parents, presumed to be heterozygotes. Measurements were made of pregnanetriol in the urine of 20 parents and of 18 normal control individuals both before and after the administration of 60 to 80 units of ACTH. The increments in the amount of this compound excreted in the urine of the parents were compared with those of the controls. The difference was significant, at the 2 to 5 per cent level. While such a difference is not striking, it is additional suggestive evidence that virilizing adrenal hyperplasia is a genetically determined, inborn error of adrenocortical steroidogenesis.

\section{ACKNOWLEDGMENT}

The authors gratefully acknowledge the technical assistance of Mrs. Betty Lawrence, and the helpful guidance of Dr. Lawson Wilkins. We wish to thank Dr. Alfred $\mathrm{M}$. Bongiovanni for his advice and suggestions during the course of this study.

\section{REFERENCES}

1. Wilkins, L., The Diagnosis and Treatment of Endocrine Disorders in Childhood and Adolescence, Springfield, Charles C Thomas, 1950.

2. Knudson, A. G., Jr., Mixed adrenal disease of infancy. J. Pediat., 1951, 39, 408.

3. Bentinck, R. C., Hinman, F., Sr., Lisser, H., and Traut, H. F., The familial congenital adrenal syndrome: Report of two cases and review of the literature. Postgrad. Med., 1952, 11, 301.

4. Wilkins, L., The diagnosis of the adrenogenital syndrome and its treatment with cortisone. J. Pediat., 1952, 41, 860.
5. Callow, N. H., Callow, R. K., and Emmons, C. W., Colorimetric determination of substances containing the grouping- $\mathrm{CH}_{2} \cdot \mathrm{CO}$-in urine extracts as an indication of androgen content. Biochem. J., 1938, 32, 1312.

6. Bongiovanni, A. M., and Clayton, G. W., Jr., A simplified method for the routine determination of pregnanediol and pregnanetriol in urine. Bull. Johns Hopkins Hosp., 1954, 94, 180.

7. Bongiovanni, A. M., Eberlein, W. R., and Cara, J., Studies on the metabolism of adrenal steroids in the adrenogenital syndrome. J. Clin. Endocrinol. \& Metab., 1954, 14, 409.

8. Cox, R. I., A method for the quantitative determination in urinary extracts of $C_{24} 17: 20$-dihydroxy-20methylsteroids. Biochem. J., 1952, 52, 339.

9. Wilkins L., Grumbach, M. M., Van Wyk, J. J., Shepard, T. H., and Papadatos, C., Hermaphroditism: classification, diagnosis, selection of sex and treatment. Pediatrics, 1955, 16, 287.

10. Wells, L. J., and Van Wagenen, G., Androgen-induced female pseudohermaphrodism in the monkey (Macaca Mulatta): Anatomy of the reproductive organs. Contrib. Embryol., 1954, 235, 93.

11. Jost, A., Hormonal factors in the development of the fetus. Symposia on Quantitative Biology, Cold Spring Harbor, 1954, Vol. XIX, p. 167.

12. Bartter, F. C., Albright, F., Forbes, A. P., Leaf, A., Dempsey, E., and Carroll, E., The effects of adrenocorticotrophic hormone and cortisone in the adrenogenital syndrome associated with congenital adrenal hyperplasia: an attempt to explain and correct its disordered hormonal pattern. J. Clin. Invest., 1951, 30, 237.

13. Jailer, J. W., Louchart, J., and Cahill, G. F., Adrenal virilism. II. Metabolic studies. J. Clin. Invest., 1952, 31, 880.

14. Wilkins, L., Crigler, J. F., Jr., Silverman, S. H., Gardner, L. I., and Migeon, C. J., Further studies on the treatment of congenital adrenal hyperplasia with cortisone. II. The effects of cortisone on sexual and somatic development, with an hypothesis concerning the mechanism of feminization. J. Clin. Endocrinol. \& Metab., 1952, 12, 277.

15. Kelley, V. C., Ely, R. S., and Raile, R. B., Metabolic studies in patients with congenital adrenal hyperplasia. Effects of cortisone therapy. J. Clin. Endocrinol. \& Metab., 1952, 12, 1140.

16. Morris, C. J. O. R., A proposed mechanism for the synthesis of steroids in the adrenal cortex. Ciba Foundation Coll. Endocrin., 1952, 4, 372.

17. Jailer, J. W., Virilism. Bull. New York Acad. Med., 1953, 29 (2nd series), 377.

18. Penrose, L. S., The Biology of Mental Defect, London, Sidgwick and Jackson, 1949, p. 71.

19. Hogben, L., The genetic analysis of familial traits. Single gene substitutions. J. Genetics, 1931, 25, 97.

20. Haldane, J. B. S., A method for investigating recessive characters in man. J. Genetics, 1932, 25, 251. 
21. Dahlberg, G., Inbreeding in man. Genetics, 1929, 14, 421.

22. Glass, H. B., Symposia on Quantitative Biology, Cold Spring Harbor, 1950, Vol. XV, p. 22.

23. Eastman, N. J., Williams' Obstetrics, 10th ed., New York, Appleton Century Crofts Inc., 1950, p. 477.

24. Penrose, L. S., A method of separating the relative aetiological effects of birth order and maternal age, with special reference to mongolian imbecility. Ann. Eugenics, 1934, 6, 108.

25. Hechter, O., Zaffaroni, A., Jacobsen, R. P., Levy, H., Jeanloz, R. W., Schenker, V., and Pincus, G., The nature and biogenesis of the adrenal secretory product. Recent. Progress in Hormone Res., 1951, 6, 215.

26. Wilkins, L., Bongiovanni, A. M., Clayton, G. W., Grumbach, M. M., and Van Wyk, J., Virilizing adrenal hyperplasia: its treatment with cortisone and the nature of the steroid abnormalities. Ciba Foundation Coll. Endocrin., 1955, 8, 460.

27. Eberlein, W. R., and Bongiovanni, A. M., Partial characterization of urinary adrenocortical steroids in adrenal hyperplasia. J. Clin. Invest., 1955, 34, 1337.

28. Bongiovanni, A. M., Clayton, G. W., Grumbach, M. M., and Van Wyk, J. J., Unpublished data.

29. Wilcoxon, F., Individual comparisons by ranking methods. Biometrics Bulletin, 1945, 1, 80.

30. Bongiovanni, A. M., and Eberlein, W. R., Clinical and metabolic variations in the adrenogenital syndrome. Pediatrics, 1955, 16, 629.

31. Eberlein, W. R., and Bongiovanni, A. M., Congenital adrenal hyperplasia with hypertension: Unusual steroid pattern in blood and urine. $J$. Clin. Endocrinol. \& Metab., In press. 